DOI 10.37882/2223-2982.2020.11-2.11

\title{
РЕПРЕЗЕНТАЦИЯ ПРЕДСТАВЛЕНИЙ О СОЦИАЛЬНОЙ СФЕРЕ В НЕМЕЦКОЙ И АНГЛИЙСКОЙ ЯЗЫКОВОЙ КАРТИНЕ МИРА (НА МАТЕРИАЛЕ ФРАЗЕОЛОГИЗМОВ С КОМПОНЕНТОМ-30ОНИМОМ)
}

\section{REPRESENTATION OF THE SOCIAL SPHERE IN THE GERMAN AND ENGLISH LANGUAGE PICTURE OF THE WORLD (ON THE MATERIAL OF PHRASEOLOGICAL UNITS WITH ZOONYM COMPONENT) \\ E. Lavrishcheva N. Abroskina}

Summary: The article reveals theoretical and practical issues of the representation of ideas about the social sphere in the German and English language picture of the world. Special attention is paid to the representation of ideas and work activities of a person and interpersonal relationships. Phraseological units with a zoonym component are used as research material.

Keywords: phraseological unit, zoonym, linguistic picture of the world, concept, representation.

\section{Лаврищева Екатерина Владимировна} к.фрилол.н., ФГБОУ ВО «Елецкий государственный университет им. И.А. Бунина»

eklav@mail.ru

Аброськина Наталия Борисовна

старший преподаватель, ФГБОУВО «Елецкий государственный университет им. И.А. Бунина» abroskina-19@mail.ru

Аннотация: В статье раскрываются теоретические и практические вопросы репрезентации представлений о социальной сфере в немецкой и английской языковой картине мира. Особое внимание уделяется репрезентации представлений и трудовой деятельности человека и межличностных отношениях. В качестве материала исследования используются фразеологические единицы с компонентом-зоонимом.

Ключевые слова: фразеологизм, зооним, языковая картина мира, концепт, репрезентация.

ear of smth.), a cow (do smth. until the cows come home) , a chicken (count one's chickens before they are hatched), a bull (take the bull by the horns).

Отношение к труду и в английском, и в немецком языках выражается, в первую очередь, через оппозицию «трудолюбие - лень». Можно говорить о том, что потребность трудиться, установки на трудолюбие, отношение к труду как источнику жизни и естественному состоянию человека являются традиционными установками как для английского, так и для немецкого языкового сознания: arbeiten wie ein Pferd, arbeiten wie ein Dachs; there is more than one way to skin a cat, hit the bull's eye, take the bull by the horns.

Представления о норме составляют основу картины мира, любое отклонение от нормы фиксируется и отражается в языковой картине мира. Не случайно чрезмерное усердие при выполнении работы приобретает пейоративную оценку как в английском, так и в немецком языках: run around like a headless chicken; do smth. until the cows come home; flog a dead horse; wer zwei Hasen zugleich hetzt, fängt keinen.

И в немецком, и в английском языках реализуется отрицательное отношение к лени, безделью, нежела- 
нию трудиться: frische Fische - gute Fische; die Arbeit ist kein Frosch; um der Esels Schatten zanken; das ist für die Katze; den Bock melken; wie die Katze um den heißen Brei (herum)gehen; das ist den Mäusen gepfiffen; die Schafe austreiben; sei kein Frosch!; it is enough to make a cat laugh, act the goat.

Помимо отношения человека к труду, большое значение для английского и немецкого языкового сознания имеет результативность работы, которая зависит, прежде всего, от способа ее выполнения. Отсутствие положительного результата оценивается негативно и в немецком, и в английском языках: wer den Aal hält beim Schwanz, dem bleibt er weder halb noch ganz; wer zwei Hasen zugleich hetzt, fängt keinen; das ist für die Katze; den Bock melken; das ist den Mäusen gepfiffen; sich abmühen wie der Fisch auf dem Trocknen; make a pig's ear of smth.; you can lead a horse to water but you can't make him drink; there is not a cat in hell's chance of smb. doing smth; you can't teach an old dog new tricks; flog a dead horse.

Для описания поведения человека в обществе и в английском, и в немецком языках используются следующие зооморфные лексемы: $\boldsymbol{a}$ fish/der Fisch (never offer to teach fish to swim, frische Fische - gute Fische); a horse/ das Pferd (ride two horses at the same time, auf einem fahlen Pferde reiten); a hare/der Hase (run with the hares and hunt with the hounds, wer zwei Hase zugleich hetzt, fängt keinen); a monkey /der Affe (make a monkey out of smb., einen Affen tanzen lassen); an eagle/der Adler (keep an eagle eye on smb., den Adler fliegen lehren); a goat/der Bock (act the goat, den Bock zum Gärtner machen).

Но существуют наименования животных в немецком языке, которые при описании поведения человека не являются компонентами фразеологизмов в английском языке: der Bär (einen Bären loslassen), der Fuchs (es ist ein armer Fuchs, der nur ein Loch hat), der Dachs (sich wehren wie ein Dachs), die Ratte (schlafen wie eine Ratte), der Frosch (sei kein Frosch!), die Katze (die Katze aushalten), das Schaf (die Schafe austreiben), der Spatz (die Spatzen pfeifen es von allen Dächern), der Löwe (was der Löwe nicht kann, das kann der Fuchs), der Esel (um des Esels Schatten zanken).
В свою очередь, компонентами-зоонимами английских фразеологизмов для описания поведения человека могут быть a duck (get one's ducks in a row), a bird (give smb. the bird), $\boldsymbol{a}$ wolf (throw smb. to the wolves), a goose (cook one's goose), a mouse (be quite as a mouse), a pig (squeal like a stuck pig), an ass (to save one's ass), a turkey (talk turkey), a tiger (a paper tiger), a dog (the tail wags the dog), a snake (a snake in the grass).

Немецкая и английская языковая картина мира обнаруживает значительное сходство: в обоих языках репрезентируются представления:

- о причинении вреда: cook one's goose, fight like kilkenny cats, let sleeping dog lie, give smb. the bird;

- угрозе физического насилия/физической расправы: (die) Katze (aus)halten, sich wehren wie ein Dachs, save one's butt/to save one's ass, kick ass/to kick butt;

- обмане: j-n zum Esel machen, a paper tiger, cry wolf, $j-m$ einen Bären aufbinden, a turkey shoot, monkey business;

- помощи/поддержке: get a piece of information from the horse's mouth;

- близости/отдаленности отношений между людьми: lead a cat-and-dog existence, wie Hund und Katze leben, fight like cat and dog;

- сохранении собственного достоинства: Hahn im Korb, macht mir nicht die Pferde scheu, be on one's hobby horse;

- предательстве: eine Schlange am Busen nähren, a snake in the grass, throw smb. to the wolves, change horses in the midstream, see how the cat jumps, make a monkey out of smb.;

- безразличии: kein Hahn kräht (mehr) da(r)nach, strain at a gnat and swallow a camel.

Проведённый анализ показывает, что несмотря на некоторые различия в составе фразеологических единиц с компонентом-зоонимом, наблюдается значительное сходство представлений о социальной сфере в английской и немецкой языковой картине мира. Такое сходство обусловлено совпадением социально-исторических условий жизни людей, общими закономерностями развития человеческого бытия, дающими единый опыт, единое знание «правил жизни».

ЛИТЕРАТУРА

1. Баранов, А.Н., Добровольский, Д.О. Основы фразеологии (краткий курс). Учебное пособие. М.: Флинта, 2013. 312 с.

2. Баранов, А.Н., Добровольский, Д.О. Аспекты теории фразеологии. М.: Знак, 2008. 656 с.

3. Винарева, Л.А., Янсон, В.В. Englishldioms = Английские идиомы. Казань: 000 «ИП Логос-М», 2008. 384 с.

4. Кочнова, К.А., Чанчина, А.В. Моделирование языковой картины мира: монография. Н. Новгород: НГПУ, 2015. 145 с.

5. Burger, H. Phraseologie. Eine Einführung am Beispiel des Deutschen. Berlin: Erich Scmidt Verlag GmbH\&C0., 2003. 225 S. 